\title{
Volatile species release during torrefaction of wood and its macromolecular constituents: Part 1 - Experimental study
}

\author{
Timothée Nocquet ${ }^{\mathrm{a}}$, Capucine Dupont ${ }^{\mathrm{a}, *}$, Jean-Michel Commandre ${ }^{\mathrm{b}}$, \\ Maguelone Grateau ${ }^{a}$, Sébastien Thiery ${ }^{a}$, Sylvain Salvador ${ }^{c}$ \\ ${ }^{a}$ CEA Grenoble - LITEN - Laboratory of Technology of Biomass, 17 rue des Martyrs, 38054 Grenoble Cedex 9, France \\ ${ }^{\mathrm{b}}$ CIRAD, Biomass Energy Unit, 73 Avenue Jean-François Breton, 34398 Montpellier Cedex 5, France \\ ${ }^{\mathrm{C}} \mathrm{MINES}$ ALBI, RAPSODEE, FRE CNRS 3213, France
}

Keywords:

Biomass

Cellulose

Hemicellulose

Lignin

Torrefaction

Volatiles

\begin{abstract}
A B S T R A C T
Torrefaction tests were carried out in a thermobalance and in a lab-scale device on beechwood and on its constituents - cellulose, lignin and xylan. The main volatile species measured were water, formaldehyde, acetic acid and carbon dioxide. Thanks to measurement before volatiles condensation, the yield of formaldehyde was shown to be higher than usually observed in literature. Smaller amounts of methanol, carbon monoxide, formic acid and furfural were also quantified. Each constituent did not produce all species. Beech torrefaction could be described by the summative contribution of its three constituents up to $250{ }^{\circ} \mathrm{C}$. At $280{ }^{\circ} \mathrm{C}$ and $300{ }^{\circ} \mathrm{C}$, tests performed with constituents mixtures showed that there were interactions between cellulose and the two other constituents. A hypothetical mechanism was proposed to explain these interactions.
\end{abstract}

\section{Introduction}

Coffee torrefaction is a universally well-known process for hundreds of years. Recently, biomass torrefaction has received significant interest. However, efforts of research and development are required [1].

Biomass torrefaction can be defined as a thermal process more severe than drying but smoother than pyrolysis. It is usually carried out under inert atmosphere, at atmospheric pressure, at temperatures between 200 and $300{ }^{\circ} \mathrm{C}$ and with solid residence times ranging from a few tens of minutes to several hours [1]. Under these conditions, biomass gives rise to a solid torrefied product. This solid usually constitutes more than $70 \mathrm{w} \%$ of the initial mass [2] and has properties closer to coal than raw biomass. As described by Chew and Doshi [3], the torrefied product has a brown colour, decreased $\mathrm{H} / \mathrm{C}$ and $\mathrm{O} / \mathrm{C}$ ratios, and an increased energy density. In addition, it is hydrophobic, brittle and, in comparison to raw biomass, easier to grind and to fluidize [4] and less prone to agglomerate [5]. These properties give the torrefied product advantages over raw biomass

\footnotetext{
* Corresponding author

E-mail address: capucine_dupont@hotmail.fr (C. Dupont).
}

for transportation, storage, milling and feeding. Hence, this solid appears as a good bioenergy carrier suitable for further co-firing with pulverized coal in existing large industrial facilities or gasification in entrained-flow reactors. The remaining part of the initial mass is released as volatile matter. This volatile matter is constituted of about one third of gas - mostly carbon monoxide and carbon dioxide - and two thirds of condensable species, among which about one half of water and one half of various species such as acids or aldehydes. These co-products are at the moment either removed as waste [6] or burnt to bring energy to the process [7]. They may also be recovered as high added-value "green" molecules for chemical industry [8]. Hence it is necessary for reactor design and control to be able to predict both solid and volatile species yields versus operating conditions and feedstock.

At the moment, torrefaction mechanisms are still poorly known [1] and there are only few kinetic models dedicated to biomass torrefaction [9-11]. As solid is the main product of torrefaction, the objective of these models is generally the description of solid mass loss versus time and temperature. Only Bates and Ghoniem have recently developed a model able to predict the composition of volatiles [9]. As highlighted by the authors, the main issue in the development of such model is the lack of experimental data for validation. Indeed, there is very little information available about 


\author{
Nomenclature \\ $\Delta m_{i} \quad$ mass loss of species $i$ (=beech or cellulose or \\ hemicellulose or lignin) \\ $\% \quad$ amount of species $i$ in beech (=cellulose or \\ hemicellulose or lignin) \\ wmaf\% mass percent on moisture-ash-free basis \\ w\% mass percent \\ wmf\% mass percent on moisture-free basis \\ Acronym \\ FTIR fourier transformed infra red \\ GC gas chromatograph \\ GC-MS gas chromatograph-mass spectrometer \\ STP standard temperature and pressure \\ TGA thermo gravimetric analysis
}

the volatile species emission during torrefaction. Several studies were performed in thermobalance and mainly aimed at listing the main products obtained versus temperature [12-15]. The other studies were carried out in batch reactors and aimed at obtaining a global mass balance. Condensable species were generally collected in cooling baths for further off-line weight and analysis by GC-MS (Gas Chromatography-Mass Spectrometer) while the permanent gases were measured by online GC (Gas Chromatography) analyzer. Bourgeois and Guyonnet measured the main gases carbon monoxide and carbon dioxide but only gave a qualitative and partial overview of the condensable species, that were found to be water, acetic acid, formic acid and furfural [16]. In a similar way, Chen et al. [17] gave the global yield of condensable species and then identified seventeen compounds. Bergman et al. [18] and Prins et al. [19] were the first researchers to measure in a systematic way the condensable species produced, that were carboxylic acids - in particular acetic acid - methanol, aldehydes, phenolic compounds, furfural and ketones. More recently, Commandré et al. [20] and Dupont et al. [21] have reported the measurement of condensable species for six different biomasses and have shown that both yields and composition were highly influenced by biomass type. However, the torrefaction models mentioned above generally do not describe the influence of biomass type. They consider biomass as a global solid and are thus feedstock-specific. Only Rousset et al. [11] have developed a model which could be applied to various biomasses. Their approach was based on the summative contribution of the biomass macromolecular constituents, i.e. cellulose, hemicelluloses and lignin, which are known to react differently under the effect of heat [22]. Unfortunately, this model was limited to the description of solid mass loss versus time. Moreover, the model physical meaning was disputable as its parameters were not derived from experiments on constituents. Experimental data have recently been obtained on constituents mass loss kinetics by Chen et al. [23,24]. Based on these experiments, kinetic models have been derived for each constituent. Besides, tests on a mixture of cellulose/hemicellulose/lignin in equal fractions have shown that the mass loss of the mixture after 60 min of torrefaction could be predicted by an additive law at 230,260 and $290^{\circ} \mathrm{C}$. Unfortunately, no conclusion was drawn about the absence of interactions at other residence times or for other mixtures.

Based on this background, the objective of the Part 1 of this study is to supply an original set of experimental data about volatiles production during torrefaction of biomass, of its constituents and of their mixtures. These data will be used to test the ability of the additive law on constituents to describe torrefaction and to check the existence of interactions between them. In part 2 of this study, a modelling approach will then be derived from these experimental results as an original attempt to predict both solid yield and the main volatile species yields during torrefaction versus operating conditions and biomass macromolecular composition.

\section{Materials and methods}

\subsection{Feedstock}

The biomass sample used in this study was wood extracted from one beech trunk. This trunk was harvested in the forest of Vercors in Rhône-Alpes (France). The main properties of the sample are given in Table 1. For measurements, European standards on biofuels were followed when existing, as listed in the table. For the measurement of composition in macromolecular constituents, the methods used are detailed in Ref. [25].

The macromolecular constituents of beech were obtained as follows:

- Cellulose was Avicel beech cellulose produced by the company Aldrich.

- Beech xylan produced by the company Aldrich represented hemicelluloses. This approximation seems reasonable as analyses showed that xylan constituted around $85 \mathrm{w} \%$ of the hemicelluloses in the beech sample, the rest being mainly glucomannan.

- Lignin was extracted from the beech sample by dioxane according to the milled wood lignin procedure [26]. A purity of 90 w\% was obtained. The remaining part was thought to be constituted of hemicellulose sugars.

Ash and extractives were not considered in the rest of the study for the sake of simplicity. This approximation seems reasonable as:

- Ash and extractives represent respectively less than $1 \mathrm{w} \%$ and 3 $\mathrm{w} \%$ of the total mass of solid. Hence their impact on the global mass balance is low;

- The probability of catalytic influence of ash observed in pyrolysis and gasification [27] is low under the temperature range of torrefaction, which is quite lower than that of pyrolysis $\left(>500{ }^{\circ} \mathrm{C}\right)$ and even more of gasification $\left(>800^{\circ} \mathrm{C}\right)$.

The properties of the main constituents are given in Table 1. Note the high amount of ash contained in xylan. This ash is mainly formed of sodium and can then be attributed to the extraction

Table 1

Main properties of beech and of its main constituents.

\begin{tabular}{|c|c|c|c|c|c|c|}
\hline Property & Standard & Unit & Beech & Cellulose & Xylan & Lignin \\
\hline Moisture & EN 14774-1 & w\% & 7.0 & 7.0 & 3.0 & 6.0 \\
\hline Volatile matter & XP CEN/TS 15148 & wmf\% & 84.0 & 92.6 & 76.1 & 76.5 \\
\hline Fix carbon & By difference & wmf\% & 15.1 & 7.4 & 14.1 & 23.3 \\
\hline Ash & EN 14775 & wmf\% & 0.6 & $\sim 0$ & 9.8 & 0.2 \\
\hline Cellulose & Internal method & wmf\% & $43.3^{\mathrm{a}}$ & $\mathrm{nm}^{\mathrm{b}}$ & $\mathrm{nm}$ & $\mathrm{nm}$ \\
\hline Hemicelluloses & Internal method & wmf\% & $31.1^{\mathrm{a}}$ & $\mathrm{nm}$ & $\mathrm{nm}$ & $\mathrm{nm}$ \\
\hline Lignin & TAPPI T222 om-83 & $\mathrm{wmf} \%$ & $22.0^{\mathrm{a}}$ & $\mathrm{nm}$ & $\mathrm{nm}$ & $\mathrm{nm}$ \\
\hline Extractives & Internal method & wmf\% & 3.0 & $\mathrm{~nm}$ & $\mathrm{~nm}$ & $\mathrm{~nm}$ \\
\hline C & ISO 12902 & wmaf\% & 45.9 & 42.4 & 42.2 & 57.3 \\
\hline $\mathrm{H}$ & ISO 12902 & wmaf\% & 6.3 & 6.4 & 5.9 & 6.1 \\
\hline $\mathrm{N}$ & NF M03-18 & wmaf\% & 0.3 & 0.3 & 0.3 & 0.3 \\
\hline $\mathrm{O}$ & By difference & wmaf\% & 47.6 & 50.9 & 51.6 & 36.3 \\
\hline $\begin{array}{l}\text { Lower Heating } \\
\text { Value }\end{array}$ & XP CEN/TS 14918 & $\mathrm{MJ} \mathrm{kg}^{-1}$ & 17.1 & $\mathrm{~nm}$ & $\mathrm{~nm}$ & $\mathrm{~nm}$ \\
\hline
\end{tabular}

\footnotetext{
a Normalized to $100 \%$.

b Not measured.
} 
process of xylan, which is classically performed under alkaline conditions [28].

Beech and lignin were milled below $200 \mu \mathrm{m}$ to ensure good representativeness and to avoid any heat and mass transfer limitations during experiments. No milling was required for cellulose and xylan as they were received in the form of fine powder below $200 \mu \mathrm{m}$.

Tests were carried out with constituents mixtures, i.e. cellulose/ xylan, cellulose/lignin and xylan/lignin. Mixing was carried out with a spatula. The mixture was compacted with a mortar. This two-step process was carried out three times up to obtaining a powder of homogeneous colour. The repeatability of the torrefaction experiments carried out with mixtures was comparable to the repeatability achieved with other samples.

The ratios of constituents were chosen so as to be representative of their ratios in beech, i.e. 60:40 for cellulose/xylan, 70:30 for cellulose/lignin and 60:40 for xylan/lignin.

All samples were dried at $105{ }^{\circ} \mathrm{C}$ according to the EN 14774-1 standard and then placed in a dessicator until the start of the experiment.

\subsection{Thermo gravimetric analysis}

Thermogravimetric analysis was performed to get information on solid mass evolution versus time and temperature. The thermobalance used for the tests is a TG-DSC 111 from Setaram. In this device the difference of mass between two cylindrical crucibles one empty and the other one containing the sample - is continuously measured through an electronic balance. The crucibles were of $10 \mathrm{~mm}$ height and $4 \mathrm{~mm}$ diameter. For each experiment, about $4 \mathrm{mg}$ of sample was placed in the crucible inside the furnace under a $\mathrm{N}_{2}$ flow of 0.05 L.min $^{-1}$ (STP (standard temperature and pressure)). Temperature firstly went up to $105^{\circ} \mathrm{C}$ and was kept at this temperature for $60 \mathrm{~min}$ to ensure complete drying of the sample. Then temperature rose at a rate of $40{ }^{\circ} \mathrm{C} \mathrm{min}^{-1}$ up to the torrefaction temperature, that varied between 220 and $300^{\circ} \mathrm{C}$. A plateau was then maintained at this temperature for $180 \mathrm{~min}$.

A characteristic times analysis as well as preliminary tests have shown that chemical regime was reached under the operating conditions [29].

Tests were systematically carried out twice. The absolute difference on mass loss between replicates was always below $1 \mathrm{w} \%$.

The solid mass loss was considered on dry basis, that is, after drying at $105^{\circ} \mathrm{C}$. As the heating rate was quite fast, the difference of mass loss during temperature rise was found to very small (1-2 w $\%)$, even in the worst situation - between $280{ }^{\circ} \mathrm{C}$ and $300{ }^{\circ} \mathrm{C}$ when the reaction rate was the fastest. Thus, it seemed reasonable to make an assumption of isothermal mode at torrefaction temperature when comparing the kinetics of mass loss obtained at different torrefaction plateaux.

\subsection{Tests in the lab-scale facility TORNADE}

The device TORNADE is depicted in Fig. 1. This device has been specifically designed to measure gas and condensable species yields. Its characteristics and the associated experimental procedure are described in detail in Ref. [29]. The reactor is made up of a cylindrical crucible of $2.5 \mathrm{~cm}$ diameter and $5 \mathrm{~cm}$ height. This reactor is placed inside the isothermal zone of a furnace. During the experiments, a $\mathrm{N}_{2}$ flow of $1 \mathrm{~L} \mathrm{~min}^{-1}$ (STP) was preheated and then entered the bottom of the reactor through a porous media in order to obtain a homogeneous distribution. A mass of $100-200 \mathrm{mg}$ of sample was placed on an aluminium crucible of $1.5 \mathrm{~cm}$ diameter above the porous media. At the top of the reactor, gas and condensable species went through a heated line to a Fourier Transformed Infra Red analyzer operating at $150{ }^{\circ} \mathrm{C}$ to avoid any

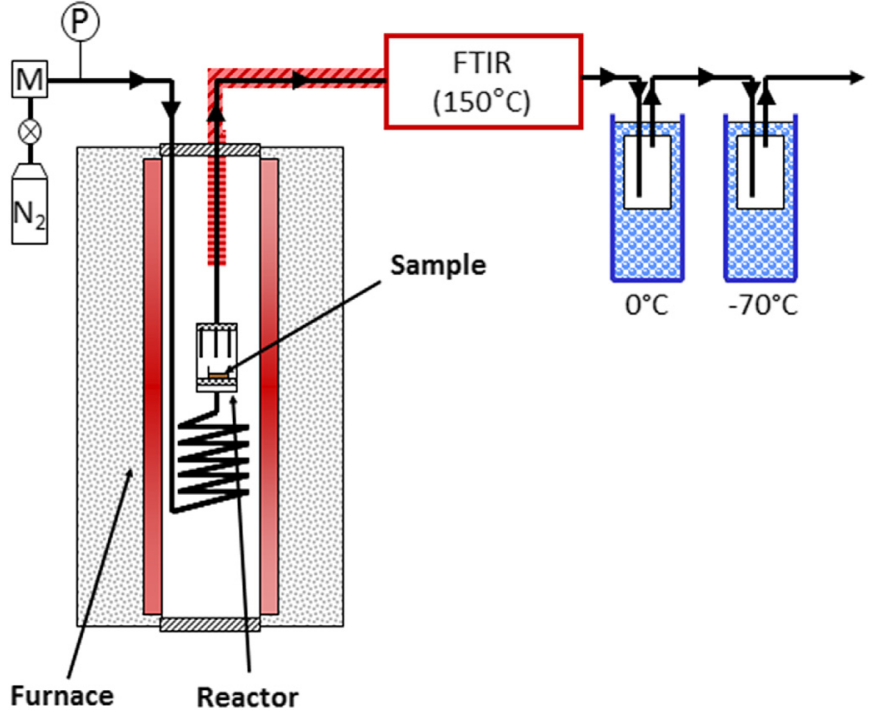

Fig. 1. Scheme of the TORNADE device.

condensation. Then, the condensable part was collected in vessels placed in two cooling baths, one containing freezing ice (wall temperature of $0{ }^{\circ} \mathrm{C}$ ) and one containing frozen carbon dioxide mixed with isopropanol (wall temperature of $-70{ }^{\circ} \mathrm{C}$ ). These vessels contained wool to increase the surface of exchange. The solid and the cooling baths were weighed before and after experiment.

The reaction temperature was defined as the average of the temperatures measured by three thermocouples of $K$ type placed above the sample. Note that the differences observed between thermocouples values were below $1^{\circ} \mathrm{C}$. The temperature profile was similar to the one used in TGA (thermo gravimetric analysis). However, due to experimental constraints, the heating rate to torrefaction temperature was of about $10{ }^{\circ} \mathrm{C} \mathrm{min}^{-1}$.

As previously, a characteristic times analysis as well as preliminary tests have shown that chemical regime was reached under the operating conditions [29].

The mass balance was closed between 97 and 104\%. These values are below the systematic error which is estimated to be of $3-5 \%$ and are thus very satisfactory.

\section{Results and discussion}

\subsection{Kinetics of solid mass loss}

As can be seen in Fig. 2, the evolution of beech mass loss versus time seems to occur in two steps whatever the temperature: first, the mass loss is relatively fast, then, it is slower but continuous until the end of the experiment. This behaviour is in agreement with literature [30].

As expected, the evolution of mass loss versus time was clearly different among constituents. For lignin, in the whole range of temperatures, the mass loss was smooth and continuous. For xylan, in the whole range of temperatures, there was firstly a very sharp mass loss followed by a plateau, with nearly no mass loss. Hence, xylan exhibited the highest mass loss for durations smaller than a few tens of min. For cellulose, two situations could be observed depending on temperature:

- At 220 and $250^{\circ} \mathrm{C}$, there was about no mass loss.

- At 280 and $300{ }^{\circ} \mathrm{C}$, cellulose had first the slowest mass loss rate but then the fastest one. At the end of the experiment, its mass loss was therefore the largest mass loss among constituents. 
a)

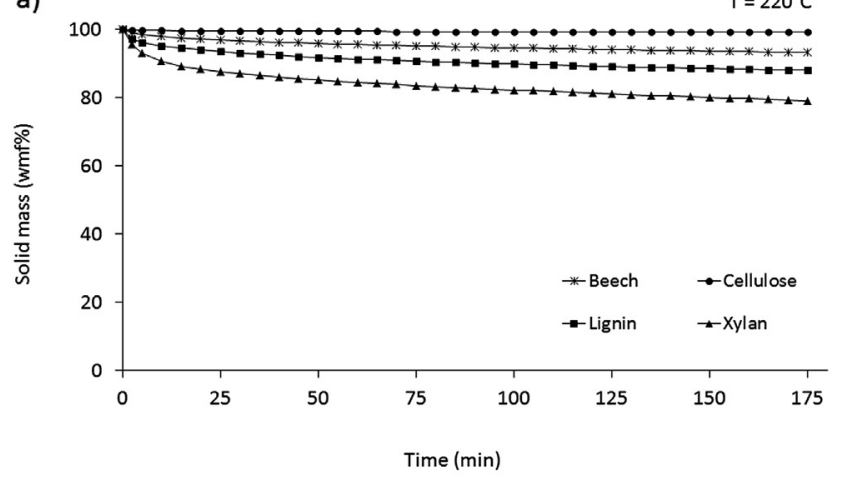

b)

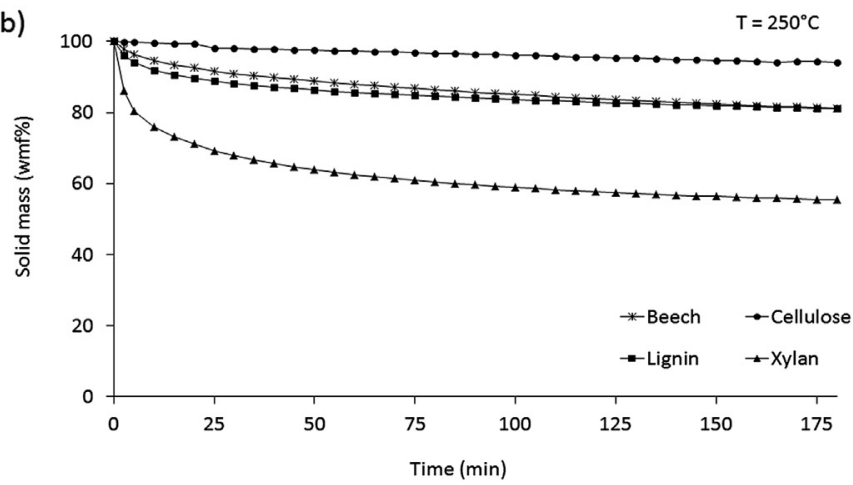

c)

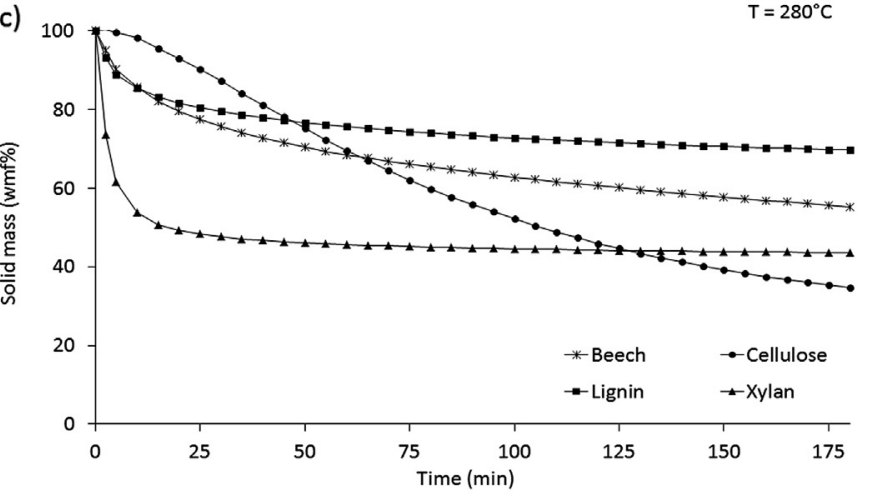

d)

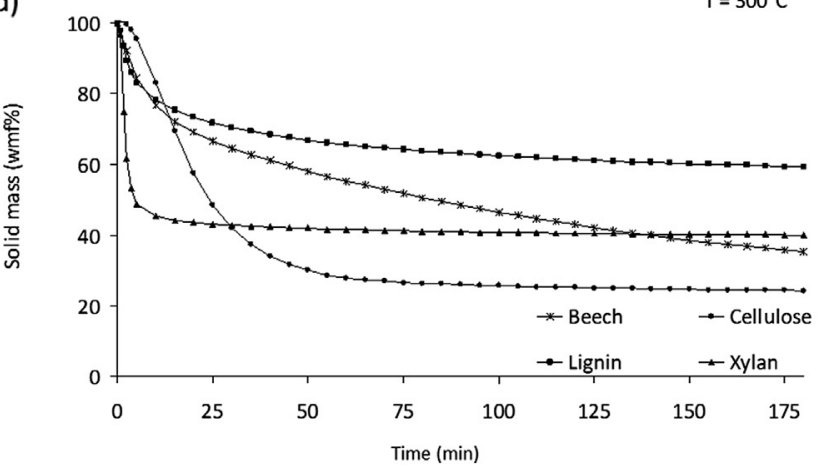

Fig. 2. Solid mass loss versus time measured in TGA device for beech, cellulose, lignin and xylan at a) $220{ }^{\circ} \mathrm{C}$; b) $250{ }^{\circ} \mathrm{C}$; c) $280{ }^{\circ} \mathrm{C}$; d) $300{ }^{\circ} \mathrm{C}$.

It is interesting to compare these results with literature on thermal decomposition of biomass constituents. The present results confirm that lignin decomposes over the widest range of temperatures among the constituents, as shown for instance by Orfão et al. [31]. However, contrary to Chen et al. [23], lignin was found to be significantly degraded in the range of torrefaction temperatures. In agreement with all authors (see for instance $[23,31,32])$, hemicellulose was found to be the less thermal stable constituent while cellulose was confirmed to be the most stable constituent. However, there is no consensus about the initial temperature of degradation, probably as its definition varies among authors. Orfão et al. [31] mentioned temperatures of first observable degradation rate of $225^{\circ} \mathrm{C}$ for cellulose and $160{ }^{\circ} \mathrm{C}$ for xylan. As in the study of Melkior et al. [32], the temperatures considered here refer to temperatures of "significant" degradation, which are logically higher. Hence, in agreement with Melkior et al. [32], hemicellulose and cellulose were found in the present study to degrade at temperatures from about $200{ }^{\circ} \mathrm{C}$ and higher than $270{ }^{\circ} \mathrm{C}$ respectively.

\subsection{Gas and condensable species yields}

As can be seen in Fig. 3a), the main species produced during beech torrefaction were water followed by formaldehyde, carbon dioxide and acetic acid. There were also significant amounts of formic acid, methanol, carbon monoxide and some traces of furfural. It can be noticed that these eight species accounted together for more than $70 \%$ of the total of volatiles produced. As expected in experiments at this low range of temperature, the amounts of methane and dihydrogen were close to zero.

The global distribution was in the same order of magnitude as in previous studies on biomass torrefaction [19-21], with about $15 \mathrm{w}$ $\%$ of permanent gas, 30 to $50 \mathrm{w} \%$ of water, and the rest of "dry" condensable species. The ratio between carbon dioxide and carbon monoxide $\mathrm{CO}_{2} / \mathrm{CO}$ decreased from 6.5 to 2.5 between $220{ }^{\circ} \mathrm{C}$ and $300^{\circ} \mathrm{C}$, which was also in agreement with literature [19]. This was also the case regarding the distribution in "dry" condensable species, except regarding formaldehyde. Indeed, this species was found to be the second most abundant species behind water in the present experiments while it was found to be only a minor species by the other authors. This difference can be attributed to a difference in the method of measurement. Indeed, authors analysed condensable species after collection in cooling baths. The condensable species with high volatility as formaldehyde were not fully kept in the cooling baths; the main part of these species remained in gas form and could not be quantified. On the contrary, in the present study, the formaldehyde measurement was performed in a hot measurement device. This measurement type avoided any disappearance of formaldehyde before analysis. Hence, this method appears to be more suitable for the measurement of such volatile species. This shows that the yield of formaldehyde - and certainly of other species with high volatility - produced during torrefaction must have been underestimated up to now in literature.

As can be seen in Fig. 3b)-d), regarding the constituents, the main result is that the species were not produced by all constituents. Hence, xylan was the main source of carbon monoxide and carbon dioxide and the only source of formic acid, in agreement with literature [16]. Formaldehyde mainly came from lignin and cellulose, which must be due to the hydroxymethyl groups $\mathrm{CH}_{2} \mathrm{OH}$ only present in these constituents. Eventually, methanol was only observed in the torrefaction of lignin and xylan, which must be due to the methoxyl groups $\mathrm{OCH}_{3}$ only present in these constituents.

A specific case was acetic acid, that was one of the main condensable products of beech torrefaction, but that was neither produced by lignin, cellulose nor xylan. In fact, this result is logical as acetic acid is known to come from the hydrolysis of the acetyl 

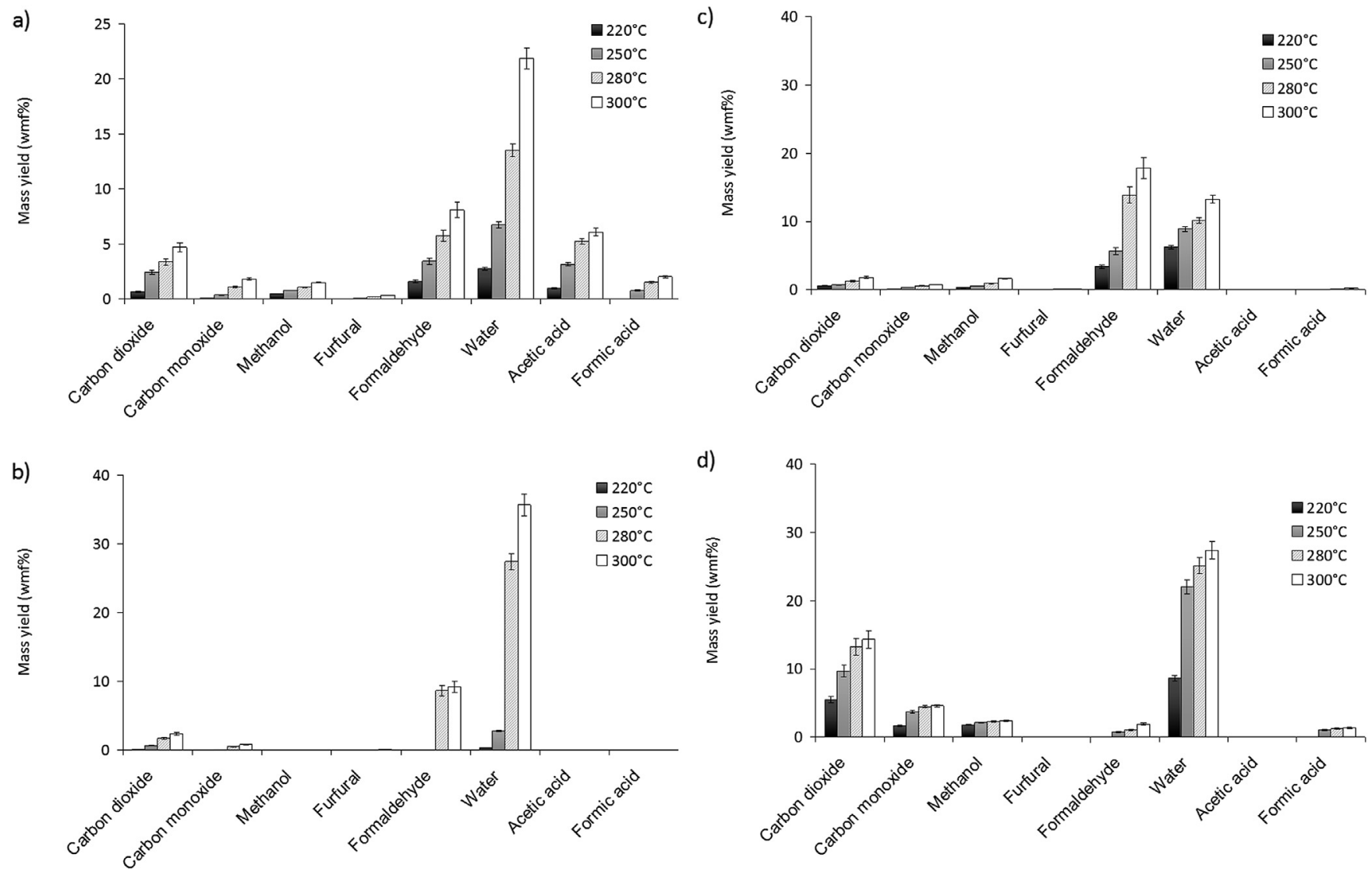

Fig. 3. Mass yields of the main volatile products measured in TORNADE at $220,250,280$ and $300{ }^{\circ} \mathrm{C}$ after 180 min for a) beech; b) cellulose; c) lignin and d) xylan.

groups $\mathrm{COCH}_{3}$ of hemicelluloses and as these groups have been removed during the extraction of xylan. This explanation was supported by the measurement of the amount of acetyl groups in beech. Indeed, their amount is of about $6 \mathrm{w} \%$, which is close to the yield of acetic acid at $300^{\circ} \mathrm{C}$.

As expected, the global yield of volatiles increased between 220 and $300{ }^{\circ} \mathrm{C}$ for beech and its constituents. The yield of each species also increased. Besides, based on these yields, the volatiles composition could be calculated: it globally remained the same whatever the temperature. The only slight differences were the decrease of formaldehyde and methanol fractions with temperature to the benefit of carbon monoxide and formic acid fractions in the case of beech, and the decrease of water to the benefit of formaldehyde in the case of lignin.

\subsection{Additive law}

A comparison was made between the experimental beech solid mass loss versus time and volatiles yields on the one hand and the prediction from the additive law on the other hand. As described in Equation (1), the additive law consists in the addition of the contribution of cellulose, lignin and xylan according to their respective amount in initial beech.

$$
\begin{aligned}
\Delta m_{\text {beech }}= & \Delta m_{\text {cellulose }} \times \% \text { cellulose }+\Delta m_{\text {hemicellulose }} \\
& \times \% \text { hemicellulose }+\Delta m_{\text {lignin }} \times \% \text { lignin }
\end{aligned}
$$

where $\Delta m_{i}$ is the mass loss of species $i$ and $\% i$ is the amount of species $i$ in initial beech.
As trends were similar, results are only shown here for solid mass loss versus time (Fig. 4).

The additive law seems to describe quite well the evolution of mass loss versus time as well as the volatile species yields up to temperatures of $250{ }^{\circ} \mathrm{C}$, with absolute differences on mass loss below a few percents. This result does not mean that the description of biomass with a mixture cellulose - lignin - xylan is a perfect representation of biomass, but this result is of interest for practical issues when one wants to predict the evolution of mass loss versus time. However, from $280{ }^{\circ} \mathrm{C}$, there are some clear discrepancies between the mass loss of beech and the additive law. For

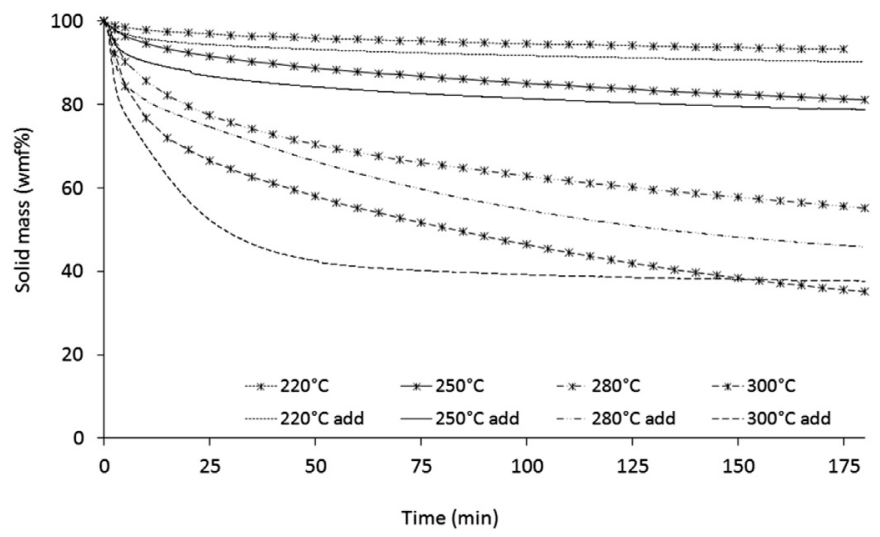

Fig. 4. Comparison of solid mass loss versus time between beech and prediction from the additive law. 

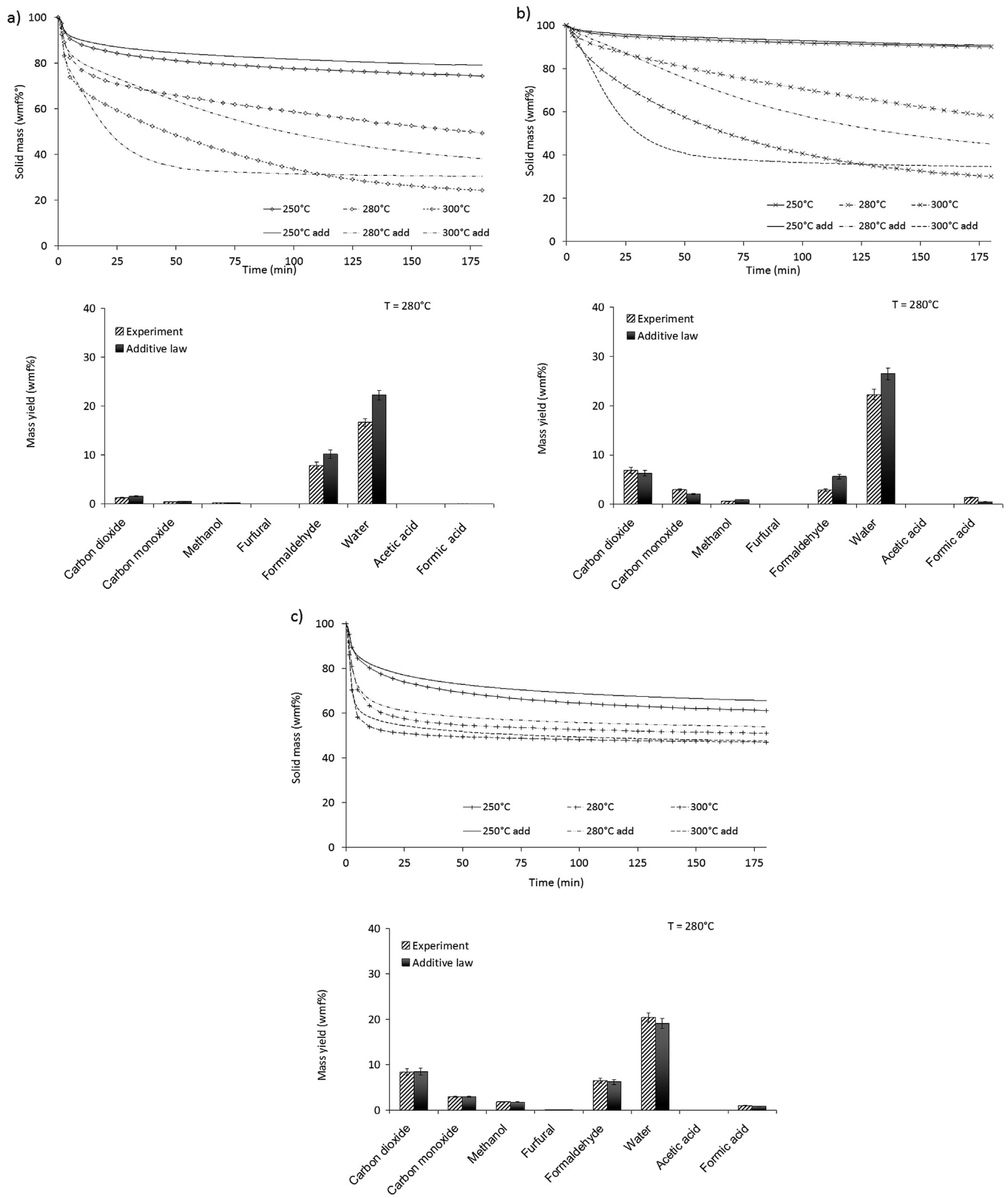

Fig. 5. Comparison between results obtained with additive law on single constituents and with mixtures a) cellulose-lignin; b) cellulose-xylan; c) lignin-xylan. Solid mass loss measured in TGA device is given versus time at three temperatures and volatile yields measured in TORNADE are given at $280{ }^{\circ} \mathrm{C}$ after 180 min. 
instance, at $300{ }^{\circ} \mathrm{C}$ after $45 \mathrm{~min}$, which is a typical torrefaction duration, the difference between the beech mass loss and the prediction from the additive law is of $16 \mathrm{w} \%$. Such difference is much higher than the experimental uncertainty and would have a great impact on process. Hence these observations tend to show that there would be interactions between constituents at $280{ }^{\circ} \mathrm{C}$ and $300{ }^{\circ} \mathrm{C}$, which make the constituents behaviour together different from their behaviour alone.

\subsection{Tests on mixtures}

Torrefaction experiments were performed on binary mixtures of constituents, i.e. cellulose/lignin, xylan/lignin, cellulose/xylan, to check the existence of interactions between constituents at temperatures of $280{ }^{\circ} \mathrm{C}$ and $300{ }^{\circ} \mathrm{C}$.

As shown in Fig. 5, a good agreement was found between the experimental and the predicted results on solid mass loss versus time and on volatile species yields for all mixtures at $250{ }^{\circ} \mathrm{C}$. This is in agreement with the absence of visible interactions between constituents observed at $250{ }^{\circ} \mathrm{C}$. This agreement between experiments and predictions could also be observed at $280^{\circ} \mathrm{C}$ and $300^{\circ} \mathrm{C}$ for the xylan/lignin mixture. On the contrary, some discrepancies could be observed both for cellulose/lignin and cellulose/xylan mixtures at $280{ }^{\circ} \mathrm{C}$ and $300{ }^{\circ} \mathrm{C}$ after $10-20 \mathrm{~min}$ of torrefaction. In both cases, a decrease of the mixture decomposition rate could be seen compared to the predicted decomposition rate. Hence these experiments show that the interactions appear to be linked with cellulose decomposition and to result in a decrease of the global degradation rate.

\subsection{Discussion on the interactions}

The discrepancies observed between the experiments on beech and the predictions from the additive law led us to carry out the tests on mixtures of biomass constituents presented above. These tests were an attempt to study the interactions phenomena between constituents. We know of course that these mixtures are not perfect representations of the cellulose, lignin and hemicelluloses arrangement in wood. They are quite a simple way to model this arrangement, probably quite far from the real complexity level. For instance, the chemical bonds between constituents are not present in the mixtures since the mixtures are purely mechanical mixtures of the constituents obtained after extraction. Moreover, as xylan does not contain acetyl groups and as it does not produce therefore any acetic acid, the possible phenomenon of acid hydrolysis of the constituents has no chance to be observed.

However, even with this simple representation of the wood constituents arrangement, interactions could clearly be observed. Better understanding their origin may help to better understand what happens in real wood during torrefaction. These interactions may have different origins.

One may suggest that they would come from gas phase reactions between the volatile species produced by the different constituents inside the reactor. However, this would only lead to changes in volatile species yields and would not impact the solid mass loss. Moreover, the gas phase reactions are believed to occur slowly under such low temperature range.

Another explanation may be proposed. At the first steps of torrefaction, xylan and lignin rapidly decompose and form many free radicals, of low molecular mass and then highly mobile. At the same time, the cellulose polymer chain begins to break into high molecular mass fragments. Then, the radicals from xylan and lignin would stick themselves on the cellulose fragments. Hence, a ramified polymer of cellulose would be formed. The degradation of such polymer would be more difficult and would lead to a decrease in the cellulose decomposition rate and then to a decrease of the decomposition rates of mixtures cellulose-lignin and cellulosexylan compared with the constituents considered separately.

\section{Conclusion}

Torrefaction experiments were carried out in a thermobalance and in a laboratory-scale device on beech, on its macromolecular constituents, i.e. cellulose, xylan as representative of hemicellulose and lignin, and on their binary mixtures.

These experiments have shown that the summative contribution of the constituents could correctly describe below $250^{\circ} \mathrm{C}$ both the evolution of solid mass loss versus time and the yields of the eight main volatile species. However, the additive law could not be applied at $280{ }^{\circ} \mathrm{C}$ and $300{ }^{\circ} \mathrm{C}$. Tests on mixtures have shown that this absence of additive behaviour could be attributed to interactions between cellulose and the other constituents. These interactions may be caused by the ramification of cellulose fragments by lignin and xylan radicals produced at the beginning of torrefaction.

The eight main volatile species were water, formaldehyde, acetic acid, carbon dioxide and, in smaller amounts, methanol, carbon monoxide, formic acid and furfural. One important result, notably for process application, was that the formaldehyde amount measured was larger than usually observed in literature. This result was attributed to the original hot measurement method by FTIR (fourier transformed infra red), which avoided losses during volatiles condensation.

Besides, these tests have also shown that volatiles composition remained globally the same whatever temperature and that each volatile species was not produced by all constituents, in relation with their chemical constitutive groups.

Thanks to these experimental results, a torrefaction model of wood has been developed in part II of this paper. This model claims to propose an original and simple approach to predict both solid and the eight main volatile species yields versus temperature, residence time and wood macromolecular composition.

\section{References}

[1] Van der Stelt MJC, Gerhauser H, Kiel JHA, Ptasinski KJ. Biomass upgrading by torrefaction for the production of biofuels: a review. Biomass Bioenergy 2012;35:3748-62.

[2] Boissonnet G, Setier PA, Haarlemmer G, Dupont C. Techno-economic assessment of several biomass pretreatment chains. IWBTE; 2012.

[3] Chew JJ, Doshi V. Recent advances in biomass pretreatment - torrefaction fundamentals and technology. Renew Sustain Energy Rev 2011;15:4212-22.

[4] Svoboda K, Pohořelý M, Hartman M, Martinec J. Pretreatment and feeding of biomass for pressurized entrained flow gasification. Fuel Process Technol 2009;90:629-35.

[5] Chen W-H, Cheng W-Y, Lu K-M, Huang Y-P. An evaluation on improvement of pulverized biomass property for solid fuel through torrefaction. Appl Energy n.d.;88:3636-44.

[6] Ratte J, Fardet E, Mateos D, Héry J-S. Mathematical modelling of a continuous biomass torrefaction reactor: TORSPYD ${ }^{\mathrm{TM}}$ column. Biomass Bioenergy 2011;35:3481-95.

[7] Kiel JHA. Torrefaction for biomass upgrading into commodity fuels. In: IEA bioenergy Task 32 Workshop "Fuel storage Handl. Prep. Syst. Anal. Biomass Combust. Technol; 2007.

[8] ANR funded project|ANR - Agence Nationale de la Recherche n.d.

[9] Bates RB, Ghoniem AF. Biomass torrefaction: modeling of volatile and solid product evolution kinetics. Bioresour Technol 2012;124:460-9.

[10] Repellin V, Govin A, Rolland M, Guyonnet R. Modelling anhydrous weight loss of wood chips during torrefaction in a pilot kiln. Biomass Bioenergy 2010;34: $602-9$.

[11] Rousset P, Perre P, Turner I. Selection of a micro-particle wood pyrolysis model for use in a macroscopic transport model. Ann Sci 2005;63:1-17.

[12] Wannapeera J, Fungtammasan B, Worasuwannarak N. Effects of temperature and holding time during torrefaction on the pyrolysis behaviors of woody biomass. J Anal Appl Pyrolysis 2011:92:99-105.

[13] Repellin V. Optimisation des paramètres durée et température d'un traitement thermique du bois. Modifications des propriétés d'usage du bois en 
relation avec les modifications physico-chimiques et ultrastructurales occasionnées par le traitement thermique. Ecole des Mines de Saint-Etienne; 2006.

[14] Bridgeman TG, Jones JM, Shield I, Williams PT. Torrefaction of reed canary grass, wheat straw and willow to enhance solid fuel qualities and combustion properties. Fuel 2008;87:844-56.

[15] Phanphanich M, Mani S. Impact of torrefaction on the grindability and fuel characteristics of forest biomass. Bioresour Technol, n.d.;102:1246-53.

[16] Bourgeois J, Guyonnet R. Characterization and analysis of torrefied wood. Wood Sci Technol 1988;22:143-55.

[17] Chen W-H, Hsu H-C, Lu K-M, Lee W-J, Lin T-C. Thermal pretreatment of wood (Lauan) block by torrefaction and its influence on the properties of the biomass. Energy 2011;36:3012-21.

[18] Bergman PCA. Torrefaction for entrained-flow gasification of biomass; 2005. ECN-C-05-013.

[19] Prins MJ, Ptasinski KJ, Janssen FJJG. Torrefaction of wood: part 2. Analysis of products. J Anal Appl Pyrolysis 2006;77:35-40.

[20] Commandré JM, Rousset P, Lesueur G, Leboeuf A, Chafchaouni L. Torrefaction of biomass: influence of operating conditions on products. Waste Eng; 2010.

[21] Dupont C, Commandré JM, Pistolet L, Nocquet T, Verne-Tournon C, Da Silva Perez D, et al. TCBiomass. Torrefaction behaviour of various biomass types: kinetics of solid mass loss and release of volatiles, vol. 2011; 2011.

[22] Gaur S, Reed TB. Pyrolysis of the components of biomass. In: MD, editor. Therm. Data Nat. Synth. New York: Fuels; 1998.
[23] Chen W-H, Kuo P-C. Isothermal torrefaction kinetics of hemicellulose, cellulose, lignin and xylan using thermogravimetric analysis. Energy 2011;36: 6451-60.

[24] Chen W-H, Kuo P-C. Torrefaction and co-torrefaction characterization of hemicellulose, cellulose and lignin as well as torrefaction of some basic constituents in biomass. Energy 2011;36:803-11.

[25] Jacob S, Da Silva Perez D, Dupont C, Commandré J-M, Broust F, Carriau A et al. Short rotation forestry feedstock: influence of particle size segregation on biomass properties. Fuel 2013;111:820-8.

[26] Björkman A. Isolation of lignin from finely divided wood with neutral solvents. Nature 1954;174:1057-8.

[27] Di Blasi C. Combustion and gasification rates of lignocellulosic chars. Prog Energy Combust Sci 2009;35:121-40.

[28] Boussarsar H. Application de traitements thermiques et enzymatiques de solubilisation et saccharification de la fraction hémicellulosique en vue de la valorisation de la bagasse de canne à sucre; 2008. Reims.

[29] Nocquet T. Torréfaction du bois et de ses constituants: expériences et modélisation des rendements en matières volatiles. INP Toulouse; 2012.

[30] Prins MJ, Ptasinski KJ, Janssen FJJG. Torrefaction of wood: part 1. Weight loss kinetics. J Anal Appl Pyrolysis 2006;77:28-34.

[31] Orfão JJM, Antunes FJA, Figueiredo JL. Pyrolysis kinetics of lignocellulosic materials - three independent reactions model. Fuel 1999;78:349-58.

[32] Melkior T, Jacob S, Gerbaud G, Hediger S, Le Pape L, Bonnefois L, et al. NMR analysis of the transformation of wood constituents by torrefaction. Fuel 2012;92:271-80. 